\title{
Künstlerische Vielfalt
}

\section{Neuerwerbungen des Hölderlin-Archivs}

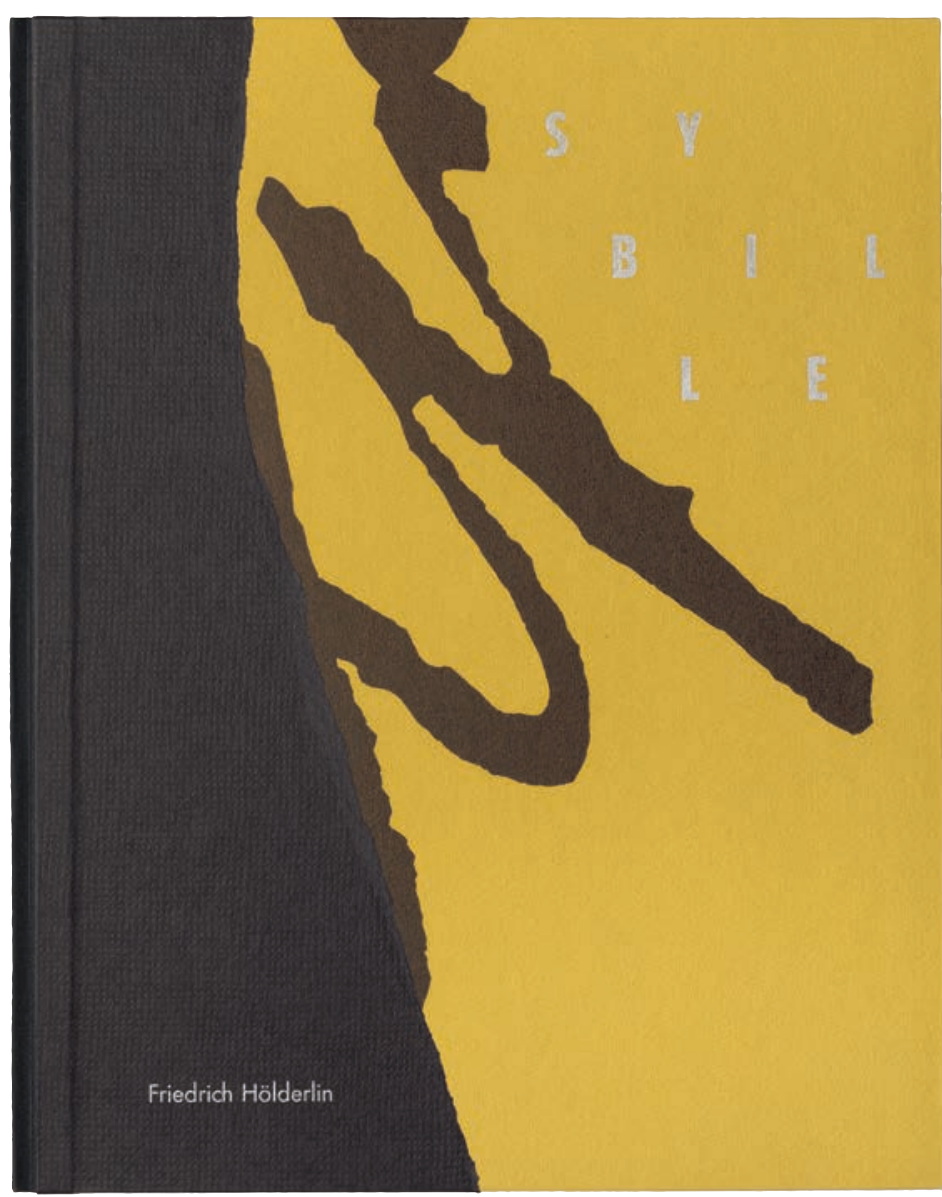

Abb. 1

Das Hölderlin-Archiv besitzt aktuell über 300 künstlerische Bücher und Drucke, die sich auf Leben und Werk des Dichters beziehen. Dazu gehören neben bibliophilen Ausgaben vor allem moderne Künstlerbücher und Druckgraphiken, die im Laufe des 20. Jahrhunderts als eigenständige Kunstwerke an die Seite der bibliophilen Ausgaben getreten sind. Auch im Jubiläumsjahr 2020 konnte das Archiv einige bemerkenswerte Ergänzungen auf diesem Gebiet vornehmen. Vorgestellt sollen im Folgenden zwei Künstlerbücher, welche die Vielschichtigkeit der Kunstrezeption belegen, sowie ein Holzschnitt.

Übergroße Fragmente einer Handschrift Friedrich Hölderlins aus dem November 1799, die als „Bruchstück 23“ in die Stuttgarter Ausgabe eingegangen sind, prägen das Buch "Sybille" der
Künstlerin Anja Harms (Abb. 1). Diese verwendet zweifarbige, auf handgeschöpftem Kupferdruckbütten gedruckte Linolschnitte, um sie dem von Hand gesetzten Text gegenüberzustellen, der beidseitig auf Transparentpapier erscheint. Auch der Einband ist mehrschichtig angelegt. Der Überzug der Rückseite überdeckt collagenhaft Teile der Vorderseite. Sein gerissener Rand gibt den Blick auf einen farbigen Linolschnitt frei. Schrift und Bild möchte die Künstlerin dadurch zu einer Einheit verbinden. Das fadengeheftete Künstlerbuch ist in einer Auflage von 25 erschienen. Für Anja Harms ist gerade das Fragmentarische ein wichtiger Zielpunkt. Sie wählt bewusst einen nicht vollendeten Gedichtentwurf Hölderlins aus.

Ein weiteres Künstlerbuch, hergestellt von der Kaldewey-Press, basiert auf den Scardanelli-Gedichten Hölderlins. Es sind Gedichte, die Hölderlin in seinen letzten Lebensjahren im Turm in Tübingen verfasst hat. Thematischer Bezugspunkt sind die vier Jahreszeiten. Das Buch enthält acht Doppelseiten zu diesen Scardanelli-Gedichten. Sie wurden auf Bogenpapier gedruckt, das Gunnar A. Kaldewey persönlich handbemalt hat. Die individuelle Gestaltung der einzelnen Jahreszeiten zeigt sich in unterschiedlichen Pinsel-Strukturen. Es werden dabei Farben verwendet, die aus „Sennelier Pigmenten“, reinen, unverschnittenen

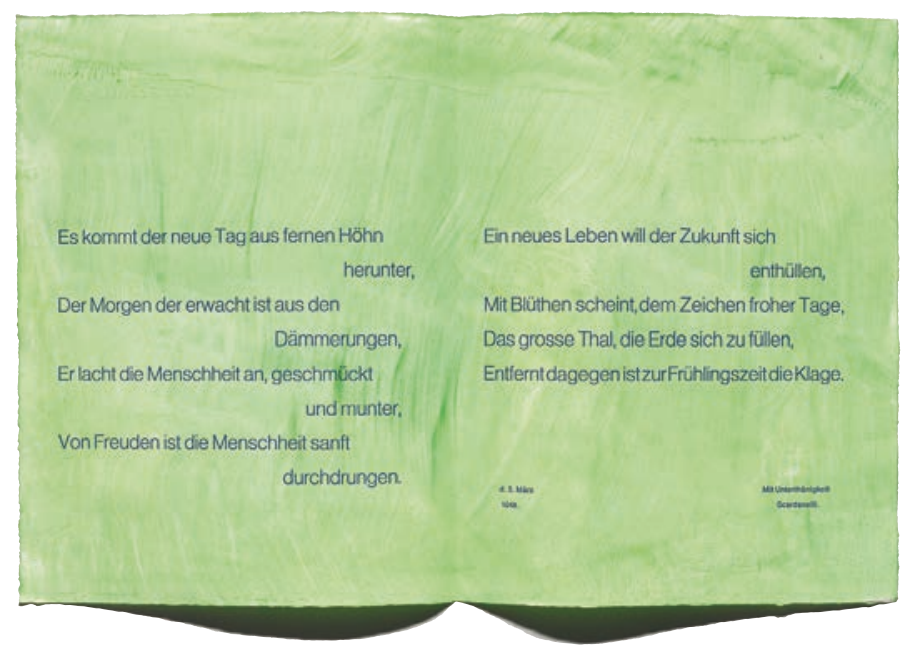

Abb. 2 
Pigmenten höchster Intensität, hergestellt worden sind. Für das Gedicht "Der Frühling“ wird passenderweise ein "Grün" verwendet (Abb. 2). Das nunmehr dritte Künstlerbuch des Hölderlin-Archivs aus dieser Handpresse ist gleichzeitig eine Bereicherung der Sammlung "Moderne Buchkunst" der WLB. Ein breites Spektrum der Bestände aus der Kaldewey-Press wurde im Jahre 2002 im Rahmen einer großen Ausstellung der Öffentlichkeit präsentiert.

Eine schöne Ergänzung stellt der Holzschnitt aus dem Jahre 1951 von Erich Heckel dar, erworben auf der Antiquariatsmesse im Januar 2021 (Abb. 3). Es handelt sich um ein Jahresblatt für 1952 mit dem Titel "Zuspruch", das als Neujahrsgruß ein
Hölderlinzitat enthält: „Geht es mit dem einen vorwärts, so wird auch der andere nicht liegen bleiben" (Brief an Casimir Ulrich Böhlendorff, 4.12.1801). Erich Heckel, der berühmte expressionistische Maler und Grafiker sowie Mitbegründer der Künstlergruppe „Brücke“, konzentriert sich hier auf die Flächigkeit des Bildes, um der ornamentalen Autonomie des Bildes mehr Gewicht zu verleihen. Aufgrund der expressiven Wirkung seiner Bilder wird der dem Südwesten, insbesondere dem Bodenseeraum verbundene Künstler auch als der "Hölderlin der Malerei" bezeichnet. Der Holzschnitt entstand in Heckels Zeit an der Akademie der Bildenden Künste in Karlsruhe, wo er von 1949-1955 einen Lehrauftrag wahrgenommen hat.

Jörg Ennen

Fotos: Rafael Glatzel

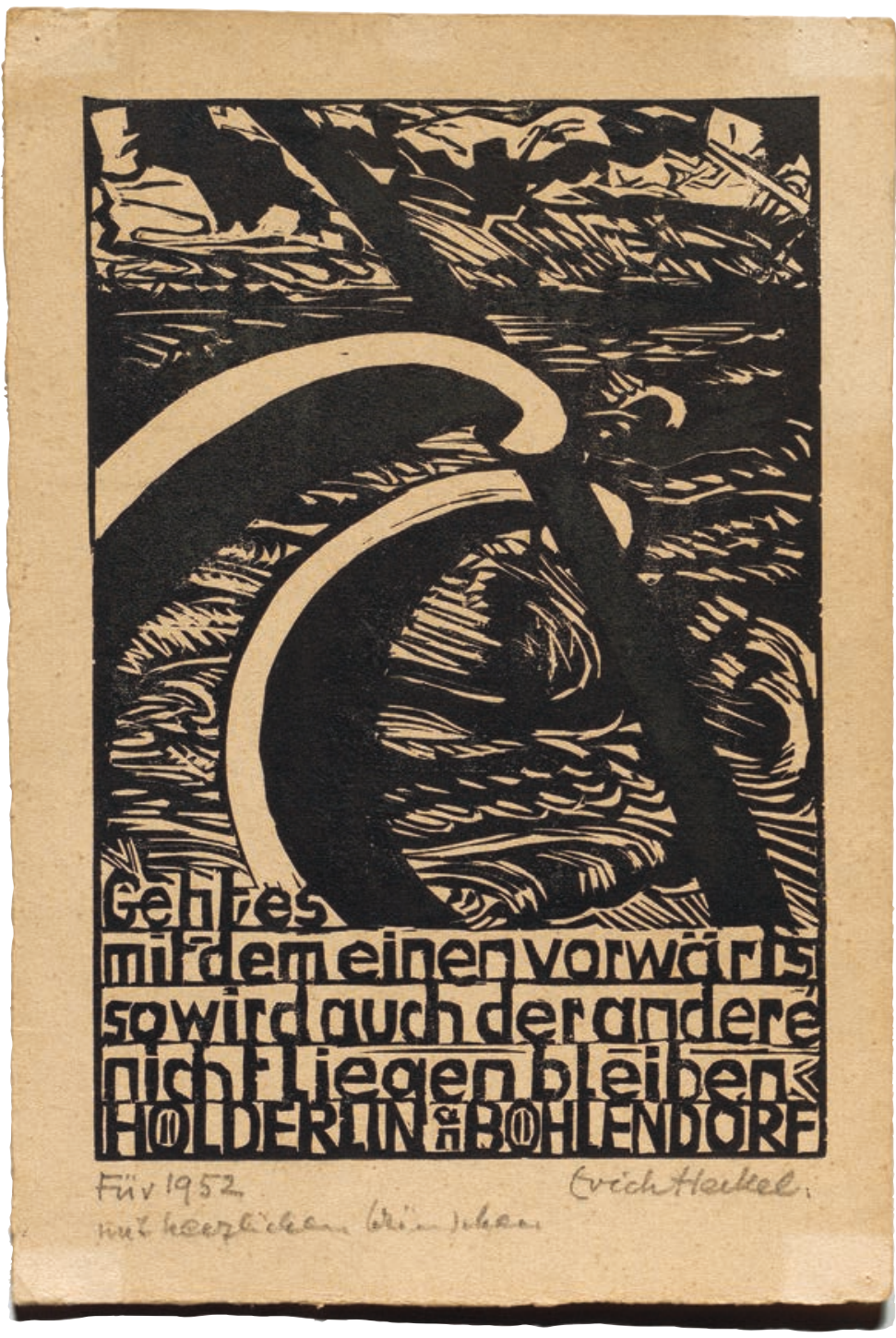

